\author{
Sebastian Rehberg \\ Christian Ertmer \\ Martin Westphal
}

\section{Mechanical ventilation in patients with ARDS: is the lung's fortune the right ventricle's poison?}

Received: 16 June 2009

Accepted: 16 June 2009

Published online: 4 August 2009

(C) Springer-Verlag 2009

This editorial refers to the article available at: doi:10.1007/s00134-009-1569-2.

S. Rehberg · C. Ertmer · M. Westphal (匹)

Department of Anesthesiology and Intensive Care,

University Hospital of Muenster, Albert-Schweitzer-Str 33,

48149 Münster, Germany

e-mail: martin.westphal@gmx.net

Tel.: +49-251-8347255

Fax: +49-251-8348667

S. Rehberg

Department of Anesthesiology, The University of Texas Medical Branch, Galveston, TX, USA

In 2000, the randomized, controlled, multicenter ARDS network study revealed a significant reduction in mortality (31 vs. $39.8 \%$ ) in patients suffering from acute lung injury (ALI) or acute respiratory distress syndrome (ARDS), who were ventilated with lower tidal volumes ( 6 vs. $12 \mathrm{ml} / \mathrm{kg}$ ) and lower plateau pressures (30 vs. $50 \mathrm{cmH}_{2} \mathrm{O}$ ) [1]. Interestingly, the associated permissive hypercapnic acidosis has been shown to provide beneficial effects on pulmonary function by interacting with reactive oxygen species, the immune system and the lung barrier [2]. Consequently, the concept of hypercapnic acidosis has turned from a tolerated side effect into a therapeutic approach. The most beneficial level of positive end-expiratory pressure (PEEP), however, is still subject to controversial discussions. A recent meta-analysis demonstrated a significant reduction in hospital mortality in favor of higher PEEP levels $(\mathrm{RR}=0.89 ; 95 \%$ CI $0.80-0.99 ; p=0.03$ ) [3]. However, several randomized, controlled, multicenter trials were not able to verify a superiority of higher vs. lower PEEP levels in respect to survival of ARDS patients [4, 5].

In the current issue of Intensive Care Medicine, Dr. Dessap and co-workers [6] investigated the effects of different PEEP levels and subsequent hypercapnic acidosis on myocardial function in patients with severe ARDS. Eleven patients were subjected to three different volumecontrolled ventilation regimes for $1 \mathrm{~h}$ each: (1) high-tidal volume $(8.5 \mathrm{ml} / \mathrm{kg})$ with low PEEP $\left(5 \mathrm{cmH}_{2} \mathrm{O}\right)$, (2) lowtidal volume $(6 \mathrm{ml} / \mathrm{kg})$ with high PEEP $\left(10-11 \mathrm{cmH}_{2} \mathrm{O}\right)$ and increased respiratory rate (30/min), and (3) low-tidal volume $(6 \mathrm{ml} / \mathrm{kg})$ with high PEEP $\left(10-11 \mathrm{cmH}_{2} \mathrm{O}\right)$ and reduced instrumental dead space. Both high PEEP strategies were associated with more severe hypercapnia and acidosis than in the low PEEP group. In addition, myocardial function, as reflected by a decreased cardiac index, as well as a lower right ventricular stroke index and left ventricular deformation, was impaired in both groups ventilated with high PEEP levels. Notably, in a multivariate analysis, only the changes in arterial $\mathrm{pH}$, but not in PEEP were significantly correlated with impaired right ventricular function. The authors concluded that hypercapnic acidosis resulting from low-tidal volume and increased PEEP contributes to impaired right ventricular function and should, therefore, only be applied with caution in patients suffering from ARDS.

The potential negative effect of hypercapnic acidosis predominantly on right ventricular function in ARDS patients, as addressed in the present study, is of special importance for two reasons: first, the right ventricle is already "stressed" secondary to lung injury and the associated increase in pulmonary vascular resistance. Second, additional impairment of right ventricular function is difficult to detect, especially in combination with acute lung injury (itself leading to increased right 
ventricular filling pressures) and an unchanged left ventricular function (suggesting an adequate contractility).

In the present study, left ventricular function was not impaired in these patients. In addition, hypovolemia was excluded by stable superior vena cava collapsibility index. Nevertheless, the cardiac index was decreased in both "high PEEP" groups, although heart rates were higher than in the low PEEP group. The authors postulate that the impaired right ventricular function was caused by increases in pulmonary vascular resistance. In this case, the lower cardiac index could be explained by a reduced left ventricular preload due to right ventricular dysfunction. A limitation of this study, however, represents the omission to determine right ventricular afterload by measuring mean pulmonary arterial pressures or tricuspid regurgitation. As a consequence, this assumption remains speculative. Based on the statistical correlation between arterial $\mathrm{pH}$ and right ventricular stroke index and supported by the rather low PEEP levels compared to previous reports [3], the authors exclude the increased PEEP levels as a causative factor for the impaired right ventricular function. To definitely discriminate the effects of PEEP and acidosis, future studies should compare hypercapnia induced by increased PEEP levels and by supplemental inspiratory carbon dioxide.

Due to the mechanistic approach of the present study, some aspects render a final conclusion about the clinical relevance of these findings elusive: First, the very short observation period of only $1 \mathrm{~h}$ does not reflect the situation of ARDS patients, who are mechanically ventilated for days or even weeks. Therefore, it needs to be clarified whether the acutely impaired right ventricular function seen in the current study recovers within some days. Second, the relevance of the impaired right ventricular function remains unclear, because potential negative effects on lactate levels, urine output or mixed venous oxygen saturation were not assessed. Last but not least, no outcome parameters have yet been determined.

Further research is warranted to explicitly clarify the influence of low-tidal volume ventilation with high PEEP levels on right ventricular function. Potential detrimental effects of hypercapnic acidosis induced right ventricular dysfunction on outcome would have to be balanced against the positive effects of higher PEEP levels on lung integrity and oxygenation. In this regard, modern inodilators, such as the calcium sensitizer levosimendan, may represent a promising approach to reduce right ventricular afterload and simultaneously improve right ventricular function in ARDS patients [7].

In summary, the study of Dr. Dessap and colleagues adds valuable information to our understanding of the complex interaction between mechanical ventilation and cardiopulmonary functions. Reviewing the current literature on this topic together with the work of the present authors, it is convincing that a potential impairment of right ventricular function should be critically considered when applying "protective" ventilation strategies in ARDS patients. Agog with expectation of future study results, a simplistic strategy to ventilate ARDS patients is to set maximum plateau pressures at $30 \mathrm{cmH}_{2} \mathrm{O}$ and titrate PEEP down to achieve a tidal volume of $6 \mathrm{ml} / \mathrm{kg}$ [8]. The challenge for the intensive care physicians consists in the tightrope walk to simultaneously assist the heart, the lung and whole body oxygenation.

\section{References}

1. The Acute Respiratory Distress Syndrome Network (2000) Ventilation with lower tidal volumes as compared with traditional tidal volumes for acute lung injury and the acute respiratory distress syndrome. N Engl J Med 342:1301-1308

2. Laffey J, Honan D, Hopkins N, Hyvelin JM, Boylan JF, McLoughlin P (2004) Hypercapnic acidosis attenuates endotoxin-induced acute lung injury. Am J Respir Crit Care Med 169:46-56

3. Oba Y, Thameem DM, Zaza T (2009) High levels of PEEP may improve survival in acute respiratory distress syndrome: a meta-analysis. Respir Med
4. Mercat A, Richard JC, Vielle B, Jaber S, Osman D, Diehl JL, Lefrant JY, Prat G, Richecoeur J, Nieszkowska A, Gervais C, Baudot J, Bouadma L, Brochard L, Expiratory Pressure (Express) Study Group (2008) Positive end-expiratory pressure setting in adults with acute lung injury and acute respiratory distress syndrome: a randomized controlled trial. JAMA 299:646-655

5. Brower RG, Lanken PN, MacIntyre N, Matthay MA, Morris A, Ancukiewicz M, Schoenfeld D, Thompson BT, National Heart, Lung, Blood Institute ARDS Clinical Trials Network (2004) Higher versus lower positive end-expiratory pressures in patients with the acute respiratory distress syndrome. N Engl J Med 351:327-336
6. Dessap AM, Charron C, Devaquet J, Aboab J, Jardin F, Brochard L, ViellardBaron A (2009) Impact of acute hypercapnia and augmented positive end-expiratory pressure on right ventricle function in severe acute respiratory distress syndrome. Intensive Care Med. doi: 10.1007/s00134-009-1569-2

7. Morelli A, Teboul JL, Maggiore SM, Vieillard-Baron A, Rocco M, Conti G, De Gaetano A, Picchini U, Orecchioni A, Carbone I, Tritapepe L, Pietropaoli P, Westphal M (2006) Effects of levosimendan on right ventricular afterload in patients with acute respiratory distress syndrome: a pilot study. Crit Care Med 34:2287-2293

8. Gattinoni L, Caironi P, Carlesso E (2005) How to ventilate patients with acute lung injury and acute respiratory distress syndrome. Curr Opin Crit Care 11:69-76 